\title{
LA EXCLUSIÓN DESDE LA LÓGICA DEL CAPITAL
}

\author{
JAIME OSORIO*
}

RESUMEN: El capital es una relación social que en su despliegue tiende a generar diversas formas de exclusión. Del proceso de producción, generando una población excedente desempleada o subempleada. Del consumo, creando una capacidad de producción que excede las capacidades de consumo debido a la explotación. De la comunidad política, al despolitizar la noción de ciudadanía y limitar las decisiones sobre los asuntos públicos. La exclusión en el capitalismo no es sino el resultado de una forma de inclusión en la lógica del capital, siendo el trabajador moderno la expresión fundamental del moderno homo sacer, aquel sujeto excluido por inclusión. No es por tanto un asunto ajeno a la dinámica del capital el proceso de exclusión, sino su núcleo interno que tiende a expulsar o a mantener en un exterior.

PALABRAS CLAVES: Exclusión, lógica del capital, homo sacer, comunidad.

ABSTRACT: The Capital is a social relationship that in its deployment tends to generate various forms of exclusion: The production process, generating a surplus population unemployed or underemployed. The Consumption process, that creates a production capacity that exceeds the capabilities of consumption due to exploitation. Of the political community process, that depoliticizes the concept of citizenship and limits decisions on public affairs. The exclusion of capitalism is nothing else but the result of a form of inclusion in the logic of capital, being the modern worker fundamental expression of the modern homo sacer, that person excluded by inclusion. The process of exclusion is therefore not a matter unrelated to the dynamics of capital, but its inner core that tends to expel or keep in the outside.

KEYwORDs: Exclusion, logic of capital, homo sacer, community.

\footnotetext{
* Profesor-investigador del Departamento de Relaciones Sociales, UAM-Xochimilco, correo-e: josorio@
} correo.xoc.uam.mx 
E 1 pensamiento moderno es incapaz de asumir la tensión y la negatividad inherente al mundo social y sus procesos. Por ello fija límites, establece un adentro y un afuera, y juega con categorías dicotómicas: racionalirracional, humano-inhumano, normal-patológico, incluido-excluido. Este procedimiento deriva de asumir cosas y no relaciones, y de dejar como un «algo ajeno» aquello que deviene de la esencia del orden social existente.

Lo que el capital considera y llama excluidos, marginales, los de afuera, no integrados, no son sino diversos nombres del exceso que le pertenece y que bajo esos y otros nombres presenta como extraño a la lógica de su despliegue. Esta operación se encuentra en la base de las ciencias sociales. Siempre existe un resto que la reflexión de la modernidad capitalista es incapaz de asumir, ante su dificultad de enfrentar la fractura que atraviesa el orden social que construye. Esa es la lógica que predomina en el ya enorme arsenal de estudios en donde la exclusión y/o el excluido se han convertido en objeto de reflexión.

La exclusión en el capitalismo no es sino una cara particular de la inclusión en la valorización y dominio del capital y expresa el exceso de una universalidad que integra expulsando. Esta exclusión por inclusión tiene como trasfondo en el capitalismo el ejercicio de un poder soberano que pone la vida de los trabajadores en entredicho. Este es el piso primario de toda exclusión, la que se expresa bajo diversas modalidades, algunas de las cuales analizaremos en este trabajo. Iniciaremos esta exposición estableciendo las coordenadas epistémicas que orientan esta reflexión, asunto necesario para comprender lo que aquí se desarrolla, así como para establecer la distancia que nos separa de otros enfoques.

\section{UN PUNTO DE PARTIDA FUNDAMENTAL: LA TOTALIDAD}

La vida entre los hombres cuenta con núcleos de organización y un problema central de las llamadas ciencias sociales es establecer los ejes en torno a los cuales ello ocurre, debiendo responder por lo que articula, jerarquiza, le da lógica y sentido a la organización que se establece. A ello remite la noción de totalidad. «Conocer el todo", o la totalidad, no es entonces pretender «conocerlo todo». Lo primero remite a la lógica que subyace y al sentido de los procesos que constituyen la vida social, en tanto lo segundo remite a una noción como la de completud. ${ }^{1}$

En nuestro tiempo, el eje fundamental que organiza la vida social se encuentra en el capital, esto es, en el valor que busca valorizarse. Es la lógica que guía ese objetivo insaciable la que desata un tornado que termina arrastrando y atrapando la vida entre los hombres en su vorágine y que tiñe el conjunto de la vida en socie-

\footnotetext{
1 Sobre la noción de completud véase Morin (1998). Es la confusión entre totalidad y completud la que subyace en Karl Popper y Max Weber, dos nombres centrales en la fundamentación del pensamiento prevaleciente en las ciencias sociales. Del primero véase Popper (1973). Del segundo véase Weber (1973).
} 
dad. A ello alude Marx (1971:28) cuando afirma que «el capital es la potencia económica que lo domina todo, de la sociedad burguesa».

La relación capital-trabajo no corresponde entonces a una relación cualquiera, periférica, una más, dentro de las múltiples relaciones que atraviesan la vida societal capitalista, como señalan las vertientes posestructuralistas y posmodernas. No tenemos un todo indiferenciado de relaciones. Por el contrario, estas tienen un peso constituyente y protofundante jerarquizado, porque "(en) todas las formas de sociedad existe una determinada producción que asigna a todas las otras su correspondiente influencia, y cuyas relaciones por lo tanto asignan a todas las otras el rango y la influencia». Más aún, esas relaciones constituyen «una iluminación general en la que se bañan todos los colores y (que) modifica las particularidades de éstos. Es como un éter particular que determina el peso específico de todas las formas de existencia que allí toman relieve» (Marx, 1971: 27-28). ${ }^{2}$ Esa relación constituye por tanto una matriz fundamental de la vida societal en el capitalismo. $^{3}$

El problema de un tal planteamiento es que asume que la totalidad no es una sumatoria de partes, ni una simple articulación, y mucho menos una totalidad contingente como podría asumir el posestructuralismo, para el cual «todos los elementos que entran en la lucha hegemónica (son) en principio iguales». Por el contrario, siempre hay uno «que (...) sobredetermina el horizonte mismo» $y$ "estructura de antemano el terreno (...) en el que la multitud de contenidos particulares luchan por la hegemonía» (Zizek, 2003: 321). ${ }^{4}$ El capitalismo jerarquiza relaciones sociales, establece un orden, define determinaciones, y cuenta, por tanto, con una lógica constitutiva, la valorización del capital.

Desde la lógica de un mundo social indeterminado, pura contingencia de múltiples identidades, para Ernesto Laclau no es posible pensar las ideas de totalidad (que asocia a totalitarismo), determinación, necesidad, "clases, lucha de clases $^{5}$ (y), capitalismo", los cuales -en referencia a los últimos- constituirían «fetiches despojados de significación»(Zizek, 2003: 203).

En medio de una confusión lógica entre determinación y determinismo, Laclau no «logra escapar a la dicotomía de necesidad y contingencia» y a su vez a la de «determinación e indeterminación». Así, «o hay determinación, y es determinista,

2 Ya veremos que «determinación» no es sinónimo de «determinismo», lo que conduce a múltiples equívocos.

${ }_{3}^{3}$ Para Zizek, «la estructura del universo de las mercancías y el capital (...) no consiste en una esfera empírica limitada, sino en una especie de sociotrascendental a priori, la matriz que genera la totalidad de las relaciones sociales y políticas» (Zizek, 2006: 93).

4 Aquí Zizek refuta algunas posiciones del posestructuralismo y del pensamiento de Ernesto Laclau en particular.

5 Esta última «es simplemente una especie de la política de identidad, especie que está siendo cada día menos importante» y sin «un significado preciso en el mundo contemporáneo». (Laclau, 2003: 205). Por el contrario, señala Zizek, "la proliferación (de nuevas subjetividades políticas) que parece relegar la «lucha de clases» a un papel secundario es (justamente jo) el resultado de la lucha de clases en el contexto del capitalismo global de hoy» (Zizek, 2003: 321). 
o simplemente no hay determinación alguna». Por esta vía introduce la idea de «indeterminación social» a fin de «recuperar el sujeto», agregando una nueva dicotomía: «O se reconoce que el sujeto opera de manera esencialmente contingente, o simplemente no hay sujeto alguno» (Pérez, 2008: 119).

Este entrevero encuentra solución si se reconoce que «hay posibilidad real cuando a partir de un estado del mundo pueden pasar muchas cosas, pero no cualquier cosa», como supone la contingencia e indeterminación laclauniana. En ese caso «la ley no dicta la necesidad sino sólo el límite. La ley como límite marca la diferencia entre lo posible y lo imposible». De esta forma es como puede ser pensada la libertad en tanto libertad determinada, "sin ser ahogada por el determinismo", y al sujeto en el territorio de la "posibilidad real» (Pérez, 2008: 126, subrayado nuestro). Hablar de determinación y de necesidad, entonces, no es determinismo (Pérez, 2008). ${ }^{6}$

En tanto el capital constituye una unidad económica y política, su valorización supone explotación y dominio de manera constitutiva. Es la valorización así entendida y es la inclusión en esa lógica económica y política la que permite comprender la exclusión: es dicha valorización la que «expulsa». Tenemos entonces una exclusión por inclusión. Es un estar fuera por estar dentro. Es un exterior sólo porque es al mismo tiempo interior.?

Por ello, cuando hoy las ciencias sociales y las humanidades piensan la exclusión como un elemento exterior, como un algo ajeno, sus soluciones pasan por pensar en cómo incluir lo que de suyo ya está incluido.

\section{PRINCIPALES FORMAS DE EXCLUSIÓN POR INCLUSIÓN}

\section{a) La población obrera excedente}

La presencia de una masa de trabajadores condenados al desempleo crónico o eventual, expulsados del trabajo asalariado y por ello sin dinero para acceder a un consumo básico, constituye una de las formas paradigmáticas de los estudios sobre le exclusión. Pasemos a ver las razones de su inclusión como exclusión en la valorización del capital.

El capital tiende a destinar proporciones relativas cada vez mayores de sus reinversiones a máquinas, nuevos equipos y tecnologías, el llamado capital constante, en desmedro del capital variable, aquel destinado a contratar trabajadores, a pesar de que es el trabajo vivo el que genera valor.

\footnotetext{
6 Véase en particular los puntos v y vi, Determinación y Necesidad, pp. 113-130.

7 Lo anterior significa "pensar al ser como totalidad", esto es "como interioridad pura respecto de la cual no hay exterioridad abstracta, separada. Interioridad en la cual toda exterioridad es referida. No sólo todo exterior es exterior de algo, también todo exterior no es sino lo mismo exteriorizadon (Pérez, 2008: 163).
} 
Ello es un paso necesario para elevar la productividad con el fin de incrementar el monto de valores de uso producidos en una misma unidad de tiempo, con lo cual su valor unitario tiende a descender al apropiarse de una menor cantidad de trabajo socialmente necesario. Es así como un determinado capital puede apropiarse de ganancias extraordinarias al producir por debajo del valor de sus competidores, o bien no quedar desplazado por éstos en la competencia, al producir en condiciones medias de productividad. De allí la significación y el peso que tiene la elevación de la productividad en el capitalismo ${ }^{8}$ y la tendencia a alterar a la baja el peso relativo de capital variable frente al capital constante.

La consecuencia de esta elevación de la composición orgánica es la generación de una población obrera excedente relativa, no absoluta, en tanto es excedente en relación a la demanda de mano de obra que realiza el capital. ${ }^{9}$ Esta población excedente cumple un significativo papel en la valorización, convirtiéndose «en palanca de la acumulación del capital» $\mathrm{y}$ «en una de las condiciones de vida del régimen capitalista de producción» (Marx, 1973: 535).

Primero porque eleva la oferta de mano de obra para los momentos de expansión de la acumulación, lo que permite al capital contar con brazos disponibles en tales situaciones. Pero además porque la presencia de una población excedente permite al capital presionar sobre los trabajadores activos, exacerbando las condiciones de explotación en general. El capital obtiene así «mayor cantidad de trabajo», sin gastar más en capital variable, «mediante una mayor explotación, extensiva e intensiva». De esta forma, «el mismo volumen de capital variable hace que la misma fuerza de trabajo despliegue mayor trabajo» (Marx, 1973: 538). La presión sobre los salarios no será menor, favoreciendo la elevación del trabajo excedente y de su producto, la plusvalía.

El encadenamiento entre la población obrera inactiva y la población obrera activa es sintetizada así por Marx:

El exceso de trabajo de los obreros activos engrosa las filas de su reserva, al paso que la presión reforzada que ésta ejerce sobre aquéllos, por el peso de la concurrencia, obliga a los obreros que trabajan a trabajar todavía más y a someterse a las imposiciones del capital. La existencia de un sector de la clase obrera condenado a ociosidad forzosa por el exceso de trabajo impuesto a la otra parte, se convierte en fuente de riqueza del capitalista individual, y acelera al mismo tiempo la formación del ejército industrial de reserva, en una escala proporcionada a los progresos de la acumulación social (Marx, 1973: 538-539).

Dos asuntos importa retener de lo anterior para el análisis que venimos realizando: uno, la relación -en términos de las necesidades de valorización- que el

\footnotetext{
8 «Arrancando de los fundamentos generales del sistema capitalista, el proceso de acumulación llega siempre a un punto en que el incremento de la productividad del trabajo social se convierte en la palanca más poderosa de la acumulación» (Marx, 1973: 525).

9 El tema lo desarrolla Marx (1973, t. 1. cap. XXIII).
} 
capital establece entre población obrera activa y población obrera inactiva, más allá de las formas que ésta última asuma, como luego pasaremos a ver. Dos, que para efectos de valorización, el tamaño de la población obrera excedente es un plus para dicha valorización, porque refuerza la explotación y la explotación redoblada de la población obrera activa.

Este es un elemento clave para las economías dependientes, en primer lugar porque las formas de explotación reinantes agotan prematuramente a la población activa, debido a la explotación redoblada imperante (Marini, 1973) por lo que se reclama mayor número de brazos disponibles para su reemplazo, así como para sostener la presión que haga posible aquel desfalco de vida de los productores. ${ }^{10}$ No hay por tanto factores naturales, sino sociales, operando en las enormes dimensiones que asume la población excedente en dichas economías. Pero la población excedente de la periferia también es necesaria para las operaciones de las economías centrales, en un doble sentido: capitales de estas economías se instalan en el mundo dependiente, profitando de las ventajas de explotación señaladas, ante la abundancia de mano de obra disponible. Y porque en una economía capitalista cada vez más interrelacionada, las bajas salariales en el mundo dependiente tienen efectos hacia la baja en los salarios del mundo central (por ejemplo, bajo la amenaza de que las empresas se trasladarán hacia la periferia, como ha ocurrido de manera importante en los últimos treinta años, en medio de la llamada globalización y la segmentación de los procesos productivos, como también por las masivas migraciones de trabajadores de las economías dependientes hacia las economías del mundo central).

La población obrera excedente generada por los procesos antes señalados presenta diversas formas de existencia, con agrupamientos que alcanzan mayores o menores niveles de incorporación a la producción, distinguiéndose la población flotante, la latente y la intermitente. A ellas se agregan las franjas sociales que se ubican en el pauperismo, que agrupa a trabajadores en condiciones de laborar pero que ya no encuentran lugar en la producción, los impedidos de laborar por haber sufrido accidentes en el trabajo y los que sufren enfermedades crónicas resultado de las condiciones en que se realiza la producción, y aquellos obreros «que sobreviven a la edad normal de su clase». También los huérfanos e hijos de pobres.

Si en el trabajador activo (semiactivo o inactivo por temporadas) el capital termina atrapando la corporeidad viva en tanto se posesiona materialmente de la fuerza de trabajo allí contenida, en el pauperismo la violencia y el despotismo sobre la vida se realiza como una doble exclusión: ni el cuerpo vivo ni la fuerza vital del trabajo perecieran encontrarse bajo el reino del capital y su poder despótico. Más aún, llegado a un cierto punto, el pauperismo se constituye en un lastre para aquél, lo que acentúa su apariencia de ajeneidad con la valorización, a pesar de sus inseparables vínculos e inclusión.

${ }^{10}$ El capital «no tiene inconveniente en abreviar la vida de la fuerza de trabajo, al modo que el agricultor codicioso hace dar la tierra un rendimiento intensivo desfalcando su fertilidad» (Marx, 1973: 208). 
La contradicción entre valor y valor de uso, alcanza forma aquí en la corporeidad de la clase obrera como un todo: la valorización del capital sólo es posible a condición de la negación, como valor de uso, de la fuerza de trabajo de uno de sus segmentos.

Marx establece la presencia de una ley general, absoluta, de la acumulación capitalista que «determina una acumulación de miseria equivalente a la acumulación de capital» (Marx, 1973: 547), porque «cuanto mayores son la riqueza social, el capital en funciones (...) y mayores también la magnitud absoluta del proletariado y la capacidad productiva del trabajo, tanto mayor es el ejército industrial de reserva» $y$ «cuanto mayor es este ejército de reserva en relación al ejército obrero en activo, más se extiende la masa de la superpoblación consolidada, cuya miseria se halla en razón inversa a los tormentos de su trabajo». El pauperismo oficial crece a su vez, «cuanto más crecen la miseria dentro de la clase obrera y el ejército industrial de reserva» (Marx, 1973: 546).

Es la lógica de la valorización la que se encuentra en la base de la población obrera excedente y ésta opera a su vez como basamento de la valorización. De ello da cuenta Marx cuando en referencia a «los últimos despojos» de esa población excedente, el pauperismo, señala que éste «es el asilo de inválidos del ejército obrero en activo y el peso muerto del ejército industrial de reserva». Y agrega que «su existencia va implícita en la existencia de la superpoblación relativa, su necesidad en su necesidad, y con ella constituye una de las condiciones de vida de la producción capitalista $y$ del desarrollo de la riqueza» (Marx, 1973: 545-546, subrayados nuestros). ${ }^{11}$

\section{Masa marginal y funcionalidad}

En una lectura de estos problemas, con un fuerte peso del funcionalismo en su reflexión, en los años sesenta y setenta del siglo xx emergió en América Latina la teoría de la marginalidad, cuyos basamentos de alguna forma se encuentran presentes en muchos análisis actuales sobre la llamada exclusión social.

Tal como lo señala José Nun, quien quizá realizó las formulaciones más elaboradas de esta teoría,

...el concepto de ejército industrial de reserva fue utilizado por Marx para designar los efectos funcionales de la superpoblación relativa en la fase del capitalismo que él estudió (capitalismo competitivo jo). Propuse que se denominara, en cambio, masa marginal a la parte de la superpoblación relativa que en otras situaciones (por ejemplo, en la fase del capitalismo monopólico, Jo), no producía esos efectos funcionales (Nun, 2001: 24-25).

Efectos tales como intensificar «la competencia entre los obreros» y deprimir los salarios, y mantener «disponible una masa de trabajadores» para cuando la expansión industrial lo requiera. (Nun, 2001: 24-25). ${ }^{12}$

${ }^{11}$ En relación al pauperismos Marx agrega que «el capital se las arregl(a) (...) para sacudirlos de sus hombros y echarlo sobre las espaldas de la clase obrera y de la pequeña clase media» (Marx, 1973: 546).

${ }^{12}$ Este material reúne el artículo inicial de Nun sobre el tema («Superpoblación relativa, ejército industrial de reserva y masa marginal») junto a una crítica de Fernando Henrique Cardoso, "Comentario sobre los conceptos de sobrepoblación relativa y marginalidad», que en el texto aparece 
Y agrega, unas líneas más adelante, la idea central en la discusión:

Como alguna vez apuntó Wilbert Moore, los propios funcionalistas norteamericanos (...) nunca habían llegado tan lejos: afirmaban que muchas cosas eran funcionales para la reproducción del capitalismo, no que todo le era funcional. Es lo que hicieron, en cambio, los críticos de la noción de masa marginal, que se empeñaron en demostrar que hasta el último de los campesinos sin tierra o de los vendedores ambulantes de nuestras ciudades eran no únicamente funcionales sino decisivos para la acumulación capitalista (Nun, 2001: 24-25).

A favor de Nun habría que señalar inicialmente que reconoce a lo menos que su llamada masa marginal es generada por el «sistema» (capitalista), aunque éste no precise de ella para seguir funcionando (Nun, 2001: 87), asunto que se ha perdido en la mayoría de las reflexiones actuales sobre el tema de la exclusión en su referencia a la población desempleada.

Cuando Marx analiza el tema, lo que le importa destacar es la capacidad del capital de generar una población excedente más allá de las tasas de natalidad que presente la población obrera, con lo cual, al romper ese dique, el capital logra un nuevo estadio en el paso de la supeditación formal del trabajo a la supeditación real. Pero además no está buscando establecer cuál es la población adecuada o funcional a la acumulación. Más bien le importa poner en evidencia el papel contradictorio como opera la acumulación de capitales en el terreno de generar riqueza y desde allí cómo desata los mecanismos de generación de miseria en la sociedad. ${ }^{13}$ Es claro que en esta dinámica habrá un crecimiento de la población excedente que rebasará sus necesidades inmediatas de brazos, y que desde esa perspectiva se constituye en un «resto» no asimilable por la demanda.

Pero el papel de la población excedente en la valorización no responde exclusivamente, como sí lo establece Nun, a su posibilidad de integrarse a la producción en algún momento o en mantener una magnitud adecuada para una cierta presión sobre los trabajadores activos. Es su crecimiento el factor fundamental para elevar los tormentos de trabajo de los trabajadores activos.

Para el capital hay márgenes de población excedente que constituyen un lastre, un peso muerto que considera que podría «vivir sin ellos y (que) le gustaría hacerlo». ${ }^{14}$ Pero si lo anterior es resultado de la forma como los paupers ensucian o escandalizan su horizonte, en esquinas y cruceros urbanos, con decenas de limpiaparabrisas, vendedores ambulantes, personas que solicitan limosnas, o por los hacinamientos en zonas urbanas que perturban y reclaman servicios, ello toma otra forma cuando, por el peso de esa misma población excedente, logra pagar salarios miserables a los que se presentan a trabajar, o descarga largas o intensas jor-

simplemente como «La crítica de F.H. Cardoso», pp. 141-183, «La respuesta a la crítica» y una nueva mirada sobre el problema, ambos de Nun, bajo el título «Nueva visita a la teoría de la masa marginal».

${ }^{13}$ Este último punto ya fue señalado por Fernando Henrique Cardoso en su artículo crítico a Nun ("Comentario sobre los conceptos de sobrepoblación relativa y marginalidad»).

${ }^{14}$ Nun cita aquí a Ralf Dahrendorf, autor de la noción de undercclass (Nun, 2001: 31). 
nadas sobre las espaldas de estos mismos trabajadores. En el fondo los rechaza, pero al mismo tiempo los necesita para desarrollar la valorización. Constituyen entonces, como hemos visto más arriba, «una de las condiciones de vida de la producción capitalista».

El capital sufre un conflicto similar cuando sus representantes políticos deben hacer campañas proselitistas en las barriadas de paupers, caminar por sus calles, estrechar sus manos y con sus cuerpos en repulsiva cercanía escuchar sus peticiones. Pero este costo es inevitable si se trata de alcanzar votos para elecciones que permitirán ganar o legitimar la dominación. No sólo desde la economía esta población es fundamental para la valorización. También desde la política cumple papeles relevantes, lo que no significa desconocer que en ambos terrenos se hace presente una negatividad que el capital, como en tantos otros terrenos, presenta como un resto que no le pertenece y establece frente a ellos un hiato de ajeneidad, en tanto excluidos. ${ }^{15}$

\section{b) El subconsumo de la población obrera activa e inactiva}

La débil incorporación de amplias franjas sociales al consumo, subsumida en los múltiples estudios sobre la pobreza y la miseria, constituye otros de los temas privilegiados por los estudios de la llamada exclusión social. En ellos predominan las visiones que ubican esos fenómenos en ajeneidad con la dinámica del capital. Pero esos procesos no son sino otra forma de la exclusión por inclusión.

El capital presenta serias dificultades para la incorporación de los trabajadores al consumo. Ello se debe a la separación que se presenta entre la fase de la producción y la fase de la realización dentro de la reproducción. En la primera, el capital se enfrenta al trabajador como productor, por lo que allí tienden a desatarse todas las tendencias a la producción de trabajo excedente que privilegian esa capacidad del trabajo vivo, comenzando por la presión hacia el salario en la compra-venta de la fuerza de trabajo. Pero en la fase de realización, el capital se enfrenta al problema que el cúmulo de mercancías lanzadas al mercado reclaman compradores, por lo cual ahora privilegia en el trabajador su condición de consumidor y espera que aquel cuente con una masa dineraria importante para que sus mercancías encuentren realización. ${ }^{16} \mathrm{El}$ problema es que cada capital quisiera privilegiar con sus

\footnotetext{
${ }^{15}$ En la lógica de la funcionalidad y disfuncionalidad propuesta por Nun, también se podría señalar que el proletariado sería funcional cuando el capital compra su fuerza de trabajo y lo explota. Pero ese mismo proletariado es el sepulturero del capitalismo, al decir de Marx. Por tanto encarna en sí mismo, y de manera simultánea, lo funcional y lo disfuncional como gusta distinguir el análisis funcionalista. ¿̇En qué punto hacemos el corte de lo uno y de lo otro propuesto por Nun?

${ }^{16}$ «Los obreros como compradores de mercancías, son importantes para el mercado. Pero como vendedores de la mercancía - de la fuerza de trabajo- la sociedad capitalista tiende a reducirlos al minimum del precio» (Marx, 1973: 283).
} 
obreros la condición de productores, y que los demás capitales fortalezcan la condición de consumidores de sus trabajadores.

El capital sostiene frente al trabajador una situación contradictoria y es en medio de esa contradicción que busca soluciones que permitan que crezca el trabajo excedente y a su vez la capacidad de consumo de los productores. Este conflicto alcanza menos fuerza en las economías dependientes, ya que en ellas el capital emerge y se reproduce privilegiando los mercados externos como campo de realización, ${ }^{17}$ y sólo ha reorientando la producción de sus sectores ejes de manera significativa hacia los mercados locales en momentos acotados, sea en situaciones de crisis y/o guerras en el mundo central, cuando la demanda externa de sus productos ha caído drásticamente.

Una solución a aquel conflicto, quizá la más importante, el capital la encuentra en la producción de plusvalía relativa, esto es en la elevación de la productividad, y ligado a ella, pero diferenciada, con la intensificación del trabajo. Cuando el incremento de la productividad alcanza las ramas productoras de bienes -salarios, el capital logra dentro de la jornada la reducción del tiempo de trabajo necesario (aquel en donde el productor reproduce un valor equivalente al valor de su fuerza de trabajo), y la extensión del trabajo excedente, sin modificar la duración de la jornada. Esto hace posible que crezca el consumo obrero debido al abaratamiento real de los bienes- salario, al tiempo que se incremente a su vez la producción de plusvalía. La ecuación parece encontrar una solución.

Con la intensificación del trabajo, al acelerar ritmos de producción y reducir los tiempos muertos (para la producción de plusvalor) el capital logra a su vez reducir el tiempo de trabajo necesario en relación al crecimiento del tiempo de producción de plusvalor. Sin embargo, su diferencia con la productividad es que este paso se alcanza sobre la base de un mayor desgaste del productor, lo que significa que en último término el capital se está apropiando hoy de años futuros de trabajo y de trabajo excedente que corresponde a jornadas futuras, con lo cual acorta la vida útil del productor, o desvaloriza su fuerza de trabajo al ser prematuramente agotada.

Frente a la solución lograda con la productividad, el problema es que para elevarla se requiere incrementar en términos absolutos y relativos los gastos en capital constante, en desmedro del capital variable, el cual puede crecer en términos absolutos pero disminuir en términos relativos, con lo cual se establecen las coordenadas para la producción de la superpoblación relativa, población que al quedar excluida o bien integrada débilmente a la producción, tiende a quedar excluida del mercado o integrada a su vez débilmente al mismo. Las tendencias a la expansión del mercado se topan así con su correlato que lo estrecha.

\footnotetext{
${ }^{17}$ Esto es lo que permite que la acumulación en el mundo dependiente se sustente en la superexplotación o explotación redoblada en la tesis de Marini (1973). Lo anterior no niega que se constituya un mercado interno dinámico, resultado de la demanda de quienes viven de plusvalía y renta y de altos salarios.
} 
En su despliegue histórico, en tanto sistema mundial capitalista, el capital ha logrado atemperar este conflicto por la vía de la transferencia de valor de las economías dependientes a las economías del mundo central, permitiendo ofrecer un potencial de consumo a los trabajadores del centro que va más allá que el que proviene de la simple elevación de la productividad. ${ }^{18}$ Pero sólo atempera ese conflicto, no lo soluciona y, en segundo lugar, ello ha propiciado modalidades de reproducción capitalista en el mundo dependiente en donde el consumo de la población trabajadora ha quedado estructuralmente reducido, al sostenerse dicha reproducción en la explotación redoblada o superexplotación. Con ello, nuevamente, lo que el capital ensancha en un lado lo termina de reducir en otro, ahora considerando como unidad el sistema mundial capitalista.

La expansión del trabajo excedente por la elevación de la productividad, que permite la apropiación de plusvalía extraordinaria en medio de la competencia, pone al capital frente a los límites de su reproducción, ya que propicia una caída tendencial de la tasa de ganancia y el desencadenamiento de las crisis, al propiciar una disminución relativa de la plusvalía generada en relación al total del capital movilizado para su producción.

Las crisis se expresan de muy diversos modos, según el punto del ciclo de reproducción del capital que observemos. Así tendremos una crisis de sobreproducción de capital, que no es más que un exceso relativo de capitales (exceso en relación a la tasa de ganancia); crisis de sobreproducción de mercancías, en tanto se producen muchas más mercancías que las que el mercado puede realizar; o crisis de subconsumo, si consideramos que son las constricciones que el capital establece para la expansión del mercado y en particular del consumo de los trabajadores el elemento que obstaculiza la realización. ${ }^{19}$

Las crisis ponen de manifiesto la negatividad que atraviesa la esencia del capital. Porque tenemos un exceso (relativo) de capitales por las misma causas que provocan la presencia de manera simultánea de un exceso de población, desempleada o subempleada, esto es, capitales que no serán invertidos a pesar de que existe una masa de fuerza de trabajo disponible, la sobrepoblación relativa. Pero también tenemos una sobreproducción de mercancías por las mismas tendencias que propician que grandes franjas de población no cuenten con condiciones para resolver sus necesidades básicas. ${ }^{20}$

Todo esto obedece a que hablamos de una organización en donde el capital sólo invertirá productivamente mientras considere que alcanzará ganancias, y en donde para acceder a determinado bien es necesario contar con dinero para tal fin. En pocas palabras, hay superproducción de capitales en relación a la tasa de ganancia,

${ }_{18}$ Que ello sea así de ninguna manera significa que los trabajadores del mundo central explotan a los trabajadores del mundo dependiente o periférico. Es el capital el que se apropia de trabajo ajeno. Y crea condiciones de existencia a los trabajadores del mundo imperial que van más allá de la propia explotación de la cual son objeto.

${ }^{19}$ El tema de las crisis capitalistas y sus diversas manifestaciones lo hemos abordado en Osorio (2004), cap. II, punto: «Patrón de reproducción y crisis», pp. 65-71.

${ }^{20}$ Estos problemas los analiza Marx en el El Capital, t. 3, cap. Xv, en particular en los puntos 2 y 3. 
que ha declinado y hay superproducción de mercancias frente al mercado que el capital crea, no frente a las necesidades de la sociedad en general. ${ }^{21}$

Como hemos visto, el capital crea mercado, pero lo hace sobre la base de dejar fuera del mismo, o en posiciones tangenciales, a una masa significativa de población trabajadora, a la cual excluye del consumo, al lanzarlas al desempleo crónico o temporal.

Iguales efectos provoca la contención de los salarios y mucho más si éstos alcanzan a expresarse en remuneraciones que se mueven por debajo del valor de la fuerza de trabajo, la explotación redoblada. A pesar de contar con empleo, esta población tendrá un acceso reducido, cuando no marginal al mercado. Esta tendencia, predominante en las economías dependientes, en las décadas neoliberales de fines del siglo xx y de inicio del siglo xxI, también se extendió al mundo imperialista y central, en la búsqueda de recuperar la desfalleciente tasa de ganancia, por lo que en el sistema capitalista se asiste a la paradójica situación de que la pobreza dejó de ser sinónimo de desempleo. Ahora se puede contar con empleo y sin embargo ubicarse en la franja de la pobreza.

Como puede apreciarse, en la naturaleza misma de la valorización operan mecanismos que expulsan del empleo y del consumo a franjas importantes de la población. La exclusión del trabajo y del consumo de sectores de la población, en este orden social, no obedece a un papel externo de dicha población con los movimientos del capital. Por el contrario, es su inclusión en las redes de la valorización lo que explica dicha situación.

Ello desmiente de suyo la tesis que es la ausencia de capitales o la debilidad de las inversiones la causa de aquellos procesos, particularmente en el mundo subdesarrollado y dependiente..$^{22}$ Esa tesis pudo tener algún grado de verdad en el siglo XIX y en algunas décadas iniciales del siglo xx. Pero desde mediados de ese siglo en adelante es la marcha de la acumulación de capitales la responsable de esa exclusión.

\section{c) La comunidad ilusoria o la exclusión de la comunidad}

Así como en el campo económico el capital y su lógica de valorización propicia modalidades de inclusión excluyentes, en el campo político opera en igual dirección, provocando una aritmética de «la cuenta de los que no cuentan», o de «la

${ }^{21}$ La capacidad de consumo de la sociedad «no se halla determinada ni por la capacidad productiva absoluta ni por la capacidad absoluta de consumo, sino por la capacidad de consumo a base de las condiciones antagónicas de distribución que reducen el consumo de la gran masa de la sociedad a un mínimo susceptible sólo de variación dentro de límites muy estrechos». Porque «cuanto más se desarrolla la capacidad productiva, más choca con la angosta base sobre que descansan las condiciones del consumo» (Marx, 1973, t. 3: 243, subrayados nuestros).

${ }^{22}$ Tesis que subyace en los llamados de gobiernos y organismos internacionales y empresariales locales en América Latina a atraer capitales, y a cualquier precio.

100 PRIMER SEMESTRE 2010

MIGRACIÓN Y DESARROLLO NÚM. 14 
parte de los que no tienen parte», al decir de Ranciere (1996). Veamos algunas de sus modalidades.

El Estado capitalista presenta la particularidad de aparecer como la representación soberana del conjunto de la comunidad. Su cristalización alcanza forma en la autonomía de la política que reclama el capital, y su ruptura con la economía, para hacer efectiva «la necesaria presencia como no-económico de lo político para que lo económico se pueda presentar como no-político» (Ávalos, 2007: 57).

Desde dicha ruptura el mito contractualista, en sus diferentes versiones, alimenta aquella forma de representación: la del pacto entre iguales que termina dando vida al Estado de todos, árbitro supremo que velará por el bien de los miembros de la sociedad.

Pero dicho imaginario sólo puede sostenerse en tanto se asume la ruptura anterior. Bastará pensar la política articulada a la economía para que la igualdad se desvanezca, mostrando por el contrario la enorme fractura sobre la que se sostiene la vida en común: el reino de la desigualdad y del poder. ${ }^{23}$ La política sobre estas condiciones es el espacio de una sutura imposible, que alcanza sin embargo grados diversos de posibilidad, de cohesión y de legitimidad.

La comunidad estatal no es más que una comunidad ilusoria. El Estado es exactamente su reverso obsceno, en tanto condensación de las relaciones de dominio y explotación que fundamentan el orden societal, el universal de una parte social (los dominantes) que desde sus propios intereses y con grados variados de coerción y de consenso, impone al resto (los dominados) su verdad.

La noción de ciudadanía constituye la cristalización más acabada de la ruptura entre la política y la economía, y de la representación de lo estatal como el espacio condensado de todos. ${ }^{24}$ Su expresión igualitaria (cada cabeza un voto) y de suprema intervención de los individuos en el quehacer político constituyen la expresión de lo negado, la desigualdad y la despolitización como lo verdaderamente incluido, pero como negación.

\section{d) El inmigrante y su doble exclusión}

El trabajador inmigrante pone al desnudo el proceso de exclusión económica y política constitutivo al orden del capital. Sujetos expulsados de sus tierras de origen por falta de trabajo, precario consumo, en una vida que no alcanza condi-

${ }_{23}^{23}$ ¿Cómo es que la igualdad consiste en igualdad y desigualdad?»» se pregunta Jacques Rancière, para señalar que allí se encuentra «el aprieto propio de la política, por lo cual ésta se convierte en un aprieto para la filosofía, un objeto de la filosofía» (Rancière, 1996: 8).

${ }^{24}$ La ciudadanía a su vez, cumple en la política (como el individuo libre en el mercado, en la esfera económica) con ocultar la ruptura de las relaciones sociales que constituyen a los sujetos en la vida social. El individuo se constituye de este modo en el soberano, el que elige y decide en el mercado y en la política, sin más restricciones que su buena o mala razón. Las teorías neoclásicas y la racional choice encuentran aquí su apoyo para sus formulaciones. 
ciones mínimas de sobrevivencia digna, y que se arriesgan al éxodo por alcanzar nuevas tierras. La exclusión por inclusión alcanza niveles sociales extremos, convirtiéndose en una fuerza que dispone a los inmigrantes a enfrentar toda clase de peligros naturales y sociales instalando sus vidas en un masivo sacrificio no religioso, una vida doblemente puesta en entredicho, en donde no es extraño que sucumban apenas en la travesía.

Si logran alcanzar su destino, los inmigrantes son sometidos a vergonzantes condiciones de vida y de explotación redoblada, azuzadas por su condición de verdaderos animales perseguidos, poniendo de manifiesto que sus vidas han quedado ubicadas en el lugar político de los que no cuentan. La universalidad de los derechos humanos, en su caso, queda suspendida y sólo es vigente, a lo menos en la letra, para quienes alcanzan la condición de ciudadanos. Nos encontramos así ya no con la comunidad de los humanos con derechos, sino con la franja de la comunidad de los ciudadanos con derechos, de la cual el resto queda excluido.

Lo anterior es una manifestación de la contradicción referida al despliegue del capital: su vocación planetaria, en tanto sistema mundial, pero asentada sobre el piso de Estados nacionales territorialmente acotados, base indispensable para su reproducción. Esa contradicción, que se encuentra en el centro de los conflictos emanados de la competencia entre capitales «nacionales» en el sistema mundial, se expresa en el plano político entre la universalidad de los derechos humanos y su suspensión frente a la determinación de quiénes son ciudadanos. Es la ciudadanía el paso necesario para ungirse de aquellos. ${ }^{25}$ El sin-papeles se convierte así en una figura jurídica ubicada en un limbo: humanos sin los derechos establecidos para tal condición, pero tampoco no-humanos, ya que ello significaría instalarlos en la condición de cualquier otro animal.

\section{A MODO DE CONCLUSIÓN: EL TRABAJADOR COMO MODERNO HOMO SACER ${ }^{26}$}

En la sociedad construida por el capital es el trabajador el moderno homo sacer, aquel cuya vida quienquiera puede arrebatarla sin ser considerado homicida. ${ }^{27} \mathrm{Un}$ orden social organizado en torno al hambre desenfrenada por la apropiación de trabajo excedente y que en la producción no sólo se apropia de la fuerza de trabajo sino de la corporeidad viva de sus propietarios, no puede operar sino instalando la vida de los trabajadores en entredicho.

Todos los mecanismos que para el capital se constituyen en elementos de generación de trabajo excedente, terminan revirtiéndose para los trabajadores en

\footnotetext{
${ }^{25}$ A ello refiere la frase: «los derechos de los ingleses están por encima de los derechos humanos», formulada por Benjamin Disraeli, quien desde su cargo de primer ministro jugó un papel destacado en el expansionismo del imperio británico en el último cuarto del siglo XIX.

${ }^{26} \mathrm{El}$ tema lo hemos desarrollado en Osorio (2006).

${ }^{27}$ Corresponde a una figura del derecho romano arcaico que está excluido del derecho divino y también del derecho de los hombres. Véase Agamben (2003).
}

102 PRIMER SEMESTRE 2010 
vida arrebatada por el capital, sea con salarios que no permiten recuperar las energías vitales gastadas día con día, sea por años futuros de trabajo apropiados hoy por la vía de extensas e intensas jornadas laborales. Es la propia vida, como exclusión, lo verdaderamente incluido en el reino del capital y lo que se encuentra en juego.

Es por no considerar esta relación clasista de explotación y de dominio en donde se encuentra la principal limitación de los enfoques de Foucault y Agamben sobre el biopoder. ${ }^{28} \mathrm{Al}$ dejar de lado la relación social que ilumina el resto de las relaciones en la sociedad construida por el capital y desde donde alcanza sentido su capacidad primaria de poner la vida en entredicho, ambos autores terminan despolitizando la reflexión y estableciendo -en sectores sociales como los recluidos en manicomios, «musulmanes» ${ }^{29}$ o refugiados, y en espacios como campos de concentración- una radicalidad que no encuentra articulación con el conjunto de la organización societal, desintengrando y restando inteligibilidad a los problemas abordados.

La exclusión, en cualquiera de las manifestaciones que aquí hemos considerado, no es sino la cara de una existencia incluida en la lógica del capital.

\section{BIBLIOGRAFÍA}

Agamben, Giorgio (2003), Homo sacer. El poder soberano y la nuda vida, Valencia, Pre-textos, 1998, primera reimpresión.

(2003), Estado de excepción. Homo sacer II, 1, Valencia, Pre-textos.

Ávalos, Gerardo (2007), «El despliegue político del capital», en Gerardo Ávalos y Joachim Hirsch, La politica del capital, México, UAm-Xochimilco.

Butler, Judith (2003), Ernesto Laclau y Salvoj Zizek, Contingencia, hegemonía, universalidad. Diálogos contemporáneos en la izquierda, Buenos Aires, Fondo de Cultura Económica. Esposito, Roberto (2006), Bíos. Biopolítica y filosofía, Buenos Aires, Amorrortu editores.

Foucault, Michel (2002), Defender la sociedad, México, Fondo de Cultura Económica (Argentina, 2000).

(1977), «La voluntad de poder», Historia de la sexualidad I, México, Siglo XXI Editores.

LAClau, Ernesto (2008), Debates y combates. Por un nuevo horizonte de la política, Buenos Aires, Fondo de Cultura Económica.

Marini, Ruy Mauro (1973), Dialéctica de la dependencia, México, Editorial Era.

MArX, Karl (1973), El Capital, México, Fondo de Cultura Económica, 1946, séptima reimpresión.

(1971), Grundrisse, t. I, México, Siglo XXI Editores.

MoRIn, Edgar (1998), Introducción al pensamiento complejo, Barcelona, Gedisa Editores.

${ }_{28}$ Véase Foucault, (1977 y 2002). De Agamben (2003).

${ }^{29}$ Nombre que se le otorga a los prisioneros en los campos de concentración nazi, «un ser al que la humillación, el horror y el miedo habían privado de toda conciencia y toda personalidad, hasta llevarle a la más absoluta apatía» (Agamben, 2003: 234-235). 
Nun, José (2001), Marginalidad y exclusión social, Buenos Aires, Fondo de Cultura Económica.

Osorio, Jaime (2006), «Biopoder y biocapital. El trabajador como moderno homo sacer», Argumentos, núm. 52, UAm-Xochimilco, División de Ciencias Sociales y Humanidades, septiembre-diciembre de 2006.

(2004), Crítica de la economía vulgar. Reproducción del capital y dependencia, México, Miguel Ángel Porrúa-UAZ.

Pérez Soto, Carlos (2008), Desde Hegel. Hacia una crítica radical de las ciencias sociales, México, Itaca.

Popper, Karl (1973), La miseria del historicismo, Madrid, Alianza-Taurus.

Rancière, Jacques (1996), El desacuerdo. Política y filosofía, Buenos Aires, Ediciones Nueva Visión.

Schmit, Carl (2001), «Teología política», en Héctor Orestes (selección), Carl Schmitt, teólogo de la política, México, Fondo de Cultura Económica.

Weber, Max (1973), Ensayos sobre metodología sociológica, Buenos Aires, Amorrortu Editores. Zizer, Slavoj (2006), Visión de paralaje, Buenos Aires, Fondo de Cultura Económica. 